\title{
PENINGKATAN MUTU DAN KESELAMATAN PASIEN BERDASARKAN AKREDITASI RUMAH SAKIT
}

\author{
Erta Iman Jelita Harefa/181101138
}

ertahrf08@gmail.com

\begin{abstract}
Abstrak
Latar belakang: Pada era global saat ini tuntutan masyarakat terhadap kesehatan tidak terbatas hanya pada kebutuhan untuk hidup sehat. Tuntutan masyarakat terhadap kesehatan telah berkembang menuju pada kualitas pelayanan kesehatan. Mutu pelayanan kesehatan merupakan jaminan bagi masyarakat untuk memperoleh derajat kesehatan yang optimal. Dalam rangka meningkatkan mutu pelayanan pasien dan menjamin keselamatan pasien maka rumah sakit perlu mempunyai program peningkatan mutu dan keselamatan pasien (PMKP) yang menjangkau ke seluruh unit kerja di rumah sakit.

Tujuan: Penulisan ini bertujuan untuk mengetahui dan memberi informasi tentang peningkatan mutu dan keselamatan pasien berdasarkan akreditasi rumah sakit.

Metode: Penulisan ini menggunakan metode literature review dengan pendekatan jurnal atau artikel, buku dan $e$-book yang relevan dan akurat serta berfokus pada peningkatan mutu dan keselamatan pasien berdasarkan akreditasi rumah sakit dengan menggunakan Google Scholar, Portal Garuda, dan Jurnal Keperawatan Indonesia.

Hasil: Berdasarkan hasil pencarian literatur terdapat beberapa pendoman dalam peningkatan mutu dan keselamatan pasien sebagai berikut: pengorganisasian, sistem manajemen data, pelatihan PMKP, pemilihan area prioritas, manajemen resiko, serta evaluasi dan monitoring.

Pembahasan: Mutu pelayanan rumah sakit merupakan derajat kesempurnaan pelayanan rumah sakit untuk memenuhi kebutuhan masyarakat konsumen akan pelayanan kesehatan yang sesuai dengan standar profesi dan standar akreditasi rumah sakit. Agar peningkatan mutu dan keselamatan pasien dapat berjalan baik di perlukan para tenaga kesehatan maupun staf yang ada dirumah sakit untuk mendorong pelaksanaan program dan budaya mutu dan keselamatan secara proaktif

Penutup: Berdasarkan hasil yang telah dipaparkan di atas bahwa dalam meningkatkan mutu dan keselamatan pasien di perlukan beberapa program yang akan dilaksanakan dalam setiap rumah sakit baik itu rumah sakit nasional maupun internasional.
\end{abstract}

Kata kunci: peningkatan, mutu dan keselamatan pasien, akreditasi 


\section{LATAR BELAKANG}

Pada era global saat ini tuntutan masyarakat terhadap kesehatan tidak terbatas hanya pada kebutuhan untuk hidup sehat. Tuntutan masyarakat terhadap kesehatan telah berkembang menuju pada kualitas pelayanan kesehatan. Mutu pelayanan kesehatan merupakan jaminan bagi masyarakat untuk memperoleh derajat kesehatan yang optimal (Prastiwi, 2010).

Dalam hal ini tuntutan pelayanan kesehatan sangat penting termasuk pelayanan keperawatan yang profesional dengan standar internasional. Pelayanan kesehatan tidak lagi hanya berfokus pada kepuasan pasien tetapi juga lebih berfokus mengenai keselamatan pasien (patient safety).

Untuk itu dalam mengoptimalkan mutu pelayanan dan keselamatan pasien diperlukan standar nasional akreditasi rumah sakit dalam menunjang peningkatan yang lebih baik. Akreditasi rumah sakit dilaksanakan untuk menilai kepatuhan rumah sakit.

Dalam rangka meningkatkan mutu pelayanan pasien dan menjamin keselamatan pasien maka rumah sakit perlu mempunyai program peningkatan mutu dan keselamatan pasien (PMKP) yang menjangkau ke seluruh unit kerja di rumah sakit. Untuk pelaksanaan program tersebut di perlukan koordinasi dan komunikasi yang baik antara kepala bidang/divisi medis, keperawatan, penunjang medis, administrasi, dan lainnya termasuk kepala bidang/ unit/departemen/instalasi pelayanan.

Rumah sakit memerlukan penetapan komite atau tim atau bentuk organisasi lainnya untuk mengelola program peningkatan mutu dan keselamatan pasien agar mekanisme koordinasi pelaksanaan tersebut dapat berjalan dengan baik.

Di rumah sakit banyak layanan jasa yang memiliki peran penting bagi kehidupan masyarakat. Rumah sakit merupakan tempat yang sangat kompleks yang terdapat berbagai macam obat, tes dan prosedur, banyak alat dengan teknologinya, berbagai jenis tenaga profesi dan non profesi yang siap memberikan pelayanan pasien 24 jam terus-menerus. Keberagaman dan kerutinan pelayanan tersebut apabila tidak dikelola dengan baik dapat menimbulkan peluang untuk terjadinya kesalahan pelayanan yang dapat berakibat terhadap keselamatan pasien. 


\section{TUJUAN}

Tujuan penulisan ini adalah untuk mengetahui dan memberi informasi tentang peningkatan mutu dan keselamatan pasien berdasarkan akreditasi rumah sakit.

\section{METODE}

Penulisan ini menggunakan metode literature review dengan pendekatan jurnal atau artikel, buku dan $e$-book yang relevan dan akurat serta berfokus pada peningkatan mutu dan keselamatan pasien berdasarkan akreditasi rumah sakit. Adapun jurnal atau artikel dan $e$ book yang digunakan pada literature review adalah jurnal atau artikel dan $e$ book yang didapatkan dengan menggunakan Google Scholar, Portal Garuda, dan Jurnal Keperawatan Indonesia.

\section{HASIL}

Berdasarkan hasil pencarian literatur di dapatkan beberapa pendoman dalam peningkatan mutu dan keselamatan pasien sebagai berikut:

\section{Pengorganisasian}

Dalam hal ini dilakukan pembentukan komite PMKP atau membentuk sebuah organisasi yang sesuai dengan peraturan perundang-undangan serta memberikan penanggung jawab dalam tiap unit kerja.

2. Sistem Manajemen Data

Dalam sistem ini, rumah sakit harus mempunyai referensi dan regulasi sistem manajemen data serta teknologi, fasilitas dan dukungan lain yang akan dipergunakan dalam melakukan pengumpulan data dan informasi untuk mendukung asuhan pasien, manajemen rumah sakit, pengkajian praktik profesional, serta program mutu dan keselamatan pasien secara menyeluruh.

3. Pelatihan PMKP

Hal ini diperlukan peran semua individu yang ada di rumah sakit yang terlibat dalam pengumpulan, analisis, dan validasi data telah mengikuti pelatihan PMKP khususnya tentang sistem manajemen data.

4. Pemilihan Area Prioritas

Dalam hal ini diperlukan peran komite PMKP untuk memfasilitasi pemilihan prioritas pengukuran pelayanan klinis yang akan dievaluasi, melakukan koordinasi dan integrasi kegiatan pengukuran mutu di unit pelayanan dan pelaporannya, serta melaksanakan supervisi terhadap progres pengumpulan data. 


\section{Manajemen Resiko}

Hal ini rumah sakit harus mempunyai program manajemen resiko, dasar resiko dan membuat strategi untuk mengurangi resiko serta melaksanakan tindak lanjut analisis modus dampak kegagalan.

6. Evaluasi dan Monitoring

Hal ini diperlukan pembuatan rencana perbaikan terhadap mutu dan keselamatan berdasarkan hasil capaian mutu serta menyediakan data yang menunjukkan bahwa perbaikan bersifat efektif dan berkesinambungan dan membuat laporan tentang keberhasilan terhadap perbaikan yang dilakukan.

\section{PEMBAHASAN}

Mutu pelayanan rumah sakit merupakan derajat kesempurnaan pelayanan rumah sakit untuk memenuhi kebutuhan masyarakat konsumen akan pelayanan kesehatan yang sesuai dengan standar profesi dan standar akreditasi rumah sakit.

Akreditasi rumah sakit merupakan pengakuan terhadap mutu pelayanan rumah sakit setelah dilakukan penilaian bahwa rumah sakit telah memenuhi standar akreditasi.

Standar akreditasi adalah pedoman yang berisi tingkat pencapaian yang harus dipenuhi oleh rumah sakit dalam meningkatkan mutu pelayanan dan keselamatan pasien.

Agar peningkatan mutu dan keselamatan pasien dapat berjalan baik di perlukan para tenaga kesehatan maupun staf yang ada dirumah sakit untuk mendorong pelaksanaan program dan budaya mutu dan keselamatan secara proaktif dan menggunakan data yang fokus pada prioritas masalah.

Berdasarkan hasil yang telah dipaparkan di atas bahwa dalam meningkatkan mutu dan keselamatan pasien di perlukan beberapa program.

\section{PENUTUP}

Berdasarkan hasil yang telah dipaparkan di atas bahwa dalam meningkatkan mutu dan keselamatan pasien di perlukan beberapa program yang akan dilaksanakan dalam setiap rumah sakit baik itu rumah sakit nasional maupun internasional.

Hal ini dapat dilakukan dan dicapai dengan adanya dukungan dari berbagai pihak baik pihak rumah sakit, para tenaga kesehatan maupun pihak pemerintah. 
REFERENSI

Departemen Kesehatan RI. (2008).

Panduan Nasional Keselamatan

Pasien Rumah Sakit (Patient

Safety). Jakarta: Depkes RI.

Departemen Kesehatan RI. (2008).

Upaya Peningkatan Mutu

Pelayanan Rumah Sakit. Jakarta:

Depkes RI.

Haryoso, A. A, Ayuningtyas, D. (2019).

Strategi Peningkatan Mutu dan

Keselamatan Pasien di Rumah

Sakit Umum Derah Kepulauan

Seribu Tahun 2019-2023. Jurnal

ARSI, 115-118.

Ismainar, Hetty. (2015). Keselamatan

Pasien di Rumah Sakit.

Yogyakarta: Deepublish.

Kamil, H. (2010). Patient Safety. Idea

Nursing Journal, 1-8.

Kementerian Kesehatan RI. (2008).

Keputusan Menteri Kesehatan

Nomor 129 Tahun 2008 Tentang

Standar Pelayanan Minimal

Rumah Sakit. Jakarta: Kemenkes

RI.

Machmud, R. (2008). Manajemen Mutu

Pelayanan Kesehatan. Jurnal

Kesehatan Masyarakat, 186-190.

Permenkes RI. (2011). Peraturan

Menteri Kesehatan Republik

Indonesia

Nomor
1691/Menkes/Per/VIII/2011

Tentang Keselamatan Pasien

Rumah Sakit. Jakarta: Depkes RI.

Permenkes RI. (2017). Peraturan

Menteri Kesehatan Republik

Indonesia Nomor 34 Tahun 2017

Tentang Akreditasi Rumah Sakit.

Jakarta: Depkes RI.

Permenkes RI. (2017). Peraturan

Menteri Kesehatan Republik

Indonesia Nomor 11 Tahun 2017

Tentang Keselamatan Pasien.

Jakarta: Depkes RI.

Prastiwi, E. N. (2010). Analisis Mutu

Pelayanan Intesive Care Unit

(ICU) Melalui Audit Kematian di

RSUD Kota Bekasi Tahun 2009.

Jurnal Keperawatan UI.

Simamora, R. H. (2019). Buku Ajar Pelaksanaan Identifikasi Pasien. Uwais Inspirasi Indonesia.

Simamora, R. H. (2019). Documentation of Patient Identification Into The Electronic System to Improve The Quality of Nursing Services. International Journal of Scientific \& Technology Research.

Simamora, R. H. (2019). The Influence of Training Handover Based SBAR Communication for Improving Patients Safety. 
Indian Journal of Public Health

Research \& Development.

Tutiany, Lindawati, Krisanti P. (2017).

Bahan Ajar Keperawatan:

Manajemen Keselamatan

Pasien. Jakarta: Kemenkes RI.

Utarini, A., Djasri, H. (2012).

Keselamatan Pasien dan Mutu

Pelayanan Kesehatan. Jurnal

Manajemen Pelayanan

Kesehatan, 159-160.

Wardhani, Viera. (2017). Buku Ajar Manajemen Keselamatan

Pasien. Malang: UB Press. 